\title{
Presynaptic Depression of Glutamatergic Synaptic Transmission by D1-Like Dopamine Receptor Activation in the Avian Basal Ganglia
}

\author{
Long Ding, ${ }^{2}$ David J. Perkel, ${ }^{1}$ and Michael A. Farries ${ }^{1}$ \\ ${ }^{1}$ Departments of Biology and Otolaryngology, University of Washington, Seattle, Washington 98195-6515, and 2Department of Neuroscience, University of \\ Pennsylvania, Philadelphia, Pennsylvania 19104
}

\begin{abstract}
Vocal behavior in songbirds exemplifies a rich integration of motor, cognitive, and social functions that are shared among vertebrates. As a part of the underlying neural substrate, the song system, the anterior forebrain pathway (AFP) is required for song learning and maintenance. The AFP resembles the mammalian basal ganglia-thalamocortical loop in its macroscopic organization, neuronal intrinsic properties, and microcircuitry. Area X, the first station in the AFP, is a part of the basal ganglia essential for vocal learning. It receives glutamatergic inputs from pallial structures and sends GABAergic outputs to thalamic structures. It also receives dense dopaminergic innervation from the midbrain. The role of this innervation is essentially unknown. Here we provide evidence that dopamine (DA) can modulate the glutamatergic inputs to spiny neurons in area X. In whole-cell voltage-clamp recordings from neurons in brain slices of adult zebra finches, we found that activation of D1-like DA receptors depresses ionotropic glutamatergic synaptic current in area X spiny neurons. This effect is mediated by a presynaptic site of action, mimicked by activation of adenylyl cyclase, and blocked by protein kinase A inhibitor and an adenosine A1 receptor antagonist. These results suggest that, in addition to altering the input- output function of spiny neurons by modulating their excitability, as we have shown previously, DA can directly influence the excitatory inputs to these neurons as well. Thus, DA can exert fine control over information processing through spiny neurons in area X, the dynamics of the AFP output, and ultimately song learning and maintenance.
\end{abstract}

Key words: dopamine; basal ganglia; songbird; synaptic transmission; area X; vocal learning

\section{Introduction}

Birdsong has been a good model for studies of sensorimotor learning, perceptual learning, hormonal control, and neurogenesis in vertebrates. In the underlying neural circuit, the song system (see Fig. 1), the anterior forebrain pathway is essential for song learning and maintenance but not for song production (Bottjer et al., 1984; Sohrabji et al., 1990; Scharff and Nottebohm, 1991; Brainard and Doupe, 2000). The first station of the anterior forebrain pathway is area $\mathrm{X}$, a part of the avian basal ganglia that is specialized for song-related behaviors.

Area $\mathrm{X}$ is strikingly similar to mammalian basal ganglia in its cytoarchitecture, synaptic circuitry, neurochemistry, and topographic organization (Vates and Nottebohm, 1995; Bottjer and Johnson, 1997; Reiner et al., 1998; Luo et al., 2001). In addition, spiny neurons ( $\mathrm{SNs}$ ) in area $\mathrm{X}$ show close resemblance in their intrinsic properties to the mammalian striatal medium spiny

Received March 25, 2003; revised May 8, 2003; accepted May 9, 2003

We thank members of the Perkel lab for valuable discussions and comments on this manuscript. D.J.P. is an affiliate of the Virginia Merrill Bloedel Hearing Research (enter. This work was supported by grants to D.J.P. from National Institutes of Health (NIH) (R01-MH56646) and National Science Foundation (IBN0196104), NIH/National Institute of Deafness and Other Communication Disorders P30 Core Grant DC04661, and National Research Service Award MH12640 to M.A.F.

Correspondence should be addressed to David Perkel, Departments of Biology and Otolaryngology, University of Washington, Box 356515, 1959 NE Pacific Street, HSB BB1148, Seattle, WA 98195-6515. E-mail: perkel@u.washington.edu. Copyright $\odot 2003$ Society for Neuroscience $\quad 0270-6474 / 03 / 236086-10 \$ 15.00 / 0$ projection neuron (Farries and Perkel, 2002). Both cell types receive glutamatergic inputs from pallial structures (Farries, 2002) and dense dopaminergic innervation from midbrain nuclei (Lewis et al., 1981; Bottjer, 1993; Soha et al., 1996).

Dopaminergic inputs to the basal ganglia play important roles in motor and cognitive functions in mammals (Graybiel et al., 1994; Brown et al., 1997; Schultz, 1998). The neural basis for these broad-ranged behavioral effects has been under extensive study. The role of dopamine (DA) in singing behavior is still unknown, and there have been few reports on the physiological actions of DA in the avian basal ganglia. However, the tractable singing behavior and the discrete underlying neural circuits in songbirds provide an excellent model system for elucidating the neural basis of DA functions in vertebrates in general.

We demonstrated previously that DA modulates excitability in spiny neurons ( $\mathrm{SNs}$ ) in area $\mathrm{X}$, suggesting that DA can indeed influence information processing in the song system by altering the input-output functions of SNs (Ding and Perkel, 2002). Here we report that D1-like DA receptor activation suppresses glutamatergic synaptic responses in SNs in area X of adult zebra finches. The suppression is blocked by an inhibitor of protein kinase A (PKA) and an adenosine receptor antagonist and requires a presynaptic site of action. These new results suggest that DA can further shape the output of area $\mathrm{X}$ by direct modulation of its excitatory inputs, thus exerting fine control over the dy- 
namics of the anterior forebrain pathway and ultimately the singing behavior.

\section{Materials and Methods}

Slice preparation. Adult male zebra finches (Taeniopygia guttata), obtained from two suppliers, were kept in groups of five or fewer on a 13/11 hr light/dark cycle. Slicing procedures were as described by Stark and Perkel (1999) and were approved by the Institutional Animal Care and Use Committee at the University of Washington. Briefly, a bird was anesthetized with isoflurane and decapitated. The brain was quickly removed and immersed in ice-cold artificial CSF (ACSF) containing (in mм): $119 \mathrm{NaCl}, 2.5 \mathrm{KCl}, 1.3 \mathrm{MgSO}_{4}, 2.5 \mathrm{CaCl}_{2}, 1 \mathrm{NaH}_{2} \mathrm{PO}_{4}, 16.2$ $\mathrm{NaHCO}_{3}, 11$ D-glucose, and 10 HEPES, osmolarity 288-298 mOsm. Coronal or parasagittal slices were cut at $300-400 \mu \mathrm{m}$ thickness with a Vibratome 1000 Plus (Vibratome, St. Louis, MO) in ice-cold ACSF and then transferred to a storage chamber containing ACSF heated to 30$35^{\circ} \mathrm{C}$. The storage chamber was allowed to cool to room temperature after slicing was completed. In both the storage and recording ACSF, HEPES was replaced with equi-osmolar $\mathrm{NaHCO}_{3}$. All solutions were bubbled with a $95 \% \mathrm{O}_{2}$ and $5 \% \mathrm{CO}_{2}$ mixture.

Electrophysiological recordings. Recordings started at least $1 \mathrm{hr}$ after slicing was completed. A slice was transferred to a small recording chamber perfused (flow rate: $2-3 \mathrm{ml} / \mathrm{min}$ ) with the HEPES-free ACSF containing $150 \mu \mathrm{M}$ picrotoxin (Sigma, St. Louis, MO), osmolarity 290-310 mOsm. All recordings were made at room temperature. When transilluminated, area $\mathrm{X}$ is visually identifiable as a dark region in the paleostriatal complex ventral to the lamina medullaris dorsalis. Neurons in area X were recorded using the "blind" whole-cell technique (Blanton et al., 1989) in voltage-clamp mode. Glass pipettes were pulled to have a tip of $<2 \mu \mathrm{m}$ in diameter (Micropipette puller P-97, Sutters Instrument Co., Novato, CA). Pipettes were filled with internal solution containing (in mM): 120 Cs-gluconate, 10 HEPES, 0.2 EGTA, 8 NaCl, 2 ATP, 0.3 GTP, 2 $\mathrm{MgCl}_{2}$, 5 QX-314, 10 phosphocreatine, and 10-17 biocytin, $\mathrm{pH} 7.25$ 7.35, osmolarity 288-300 mOsm. In some cases, $100-400 \mu \mathrm{M} \mathrm{Rp}-$ adenosine 3', 5' -cyclic monophosphorothioate (Rp-cAMPS) (Tocris, Ellisville, MO) was also added to the internal solution. The electrode resistance ranged from 6 to $10 \mathrm{M} \Omega$. Signals were first amplified with an Axopatch 2D (Axon Instruments, Foster City, CA) and then low-pass filtered ( $5 \mathrm{kHz}$, unless noted otherwise) and further amplified with a Brownlee Model 410 amplifier (Brownlee Precision, Santa Clara, CA). The filtered signals were digitized $(10 \mathrm{kHz}$, unless noted otherwise) with a National Instruments (Austin, TX) digitizing board and stored in a PC using a custom data acquisition program written in LabView (National Instruments) by M. A. Farries and D. J. Perkel.

Cell type identification. In area X (Fig. 1), both SNs and aspiny fast firing neurons receive glutamatergic inputs (Farries, 2002). Little knowledge exists of glutamatergic inputs to the other interneuron cell types. Because we used a cesium-based internal solution with QX-314 to obtain better voltage-clamp recordings, it was not possible to identify SNs using the common criteria such as inward rectification or delayed firing in current-clamp mode. Instead, we based our neuron identification on the following properties: (1) spontaneous activity (we observed whether the cell was spontaneously active during tight-seal formation); (2) resting potential (we recorded the resting potential immediately after gaining access to the cell); (3) intrinsic properties [after the cell was clamped at a holding potential of $-80 \mathrm{mV}$, we monitored its response to a symmetric voltage ramp (from -80 to $0 \mathrm{mV}$ and back in $600 \mathrm{msec}$; see Fig. $2 \mathrm{~A}$, inset)]; (4) morphology (we attempted to reconstruct each cell histologically after experiments were completed; see below). The first two properties were monitored because in comparison with other cell types in area $\mathrm{X}$, the $\mathrm{SN}$ is not spontaneously active and has a more hyperpolarized resting membrane potential (Farries and Perkel, 2002). The current response to the voltage ramp displays distinct profiles (see Results) that procedurally facilitate on-line cell identification.

Synaptic physiology. EPSCs were evoked at $>15 \mathrm{sec}$ intertrial intervals by electrical stimulation with bipolar stainless-steel electrodes. The stimulating electrodes were placed either in area $\mathrm{X}$ or, to distinguish the inputs from HVC (used as a proper name) versus the lateral magnocellular nucleus of the anterior neostriatum (LMAN), near the boundary of area $\mathrm{X}$ in coronal sections as shown in Figure $3 A$, on the basis of a previous description of innervation patterns (Bottjer et al., 1989). Recording pipettes (data not shown) were placed near and ventral to the stimulating electrodes in most cases. The spatial relationship between the stimulating and recording electrodes in the other axes varied.

Putative monosynaptic EPSCs were identified by their short and stable latency and in some cases by their ability to follow high-frequency stimulus trains up to $50 \mathrm{~Hz}$. NMDA and non-NMDA ionotropic (nonNMDA) glutamate receptor-mediated EPSCs were assessed at holding potentials of depolarized values (more than or equal to $-40 \mathrm{mV}$ ) and $-80 \mathrm{mV}$, respectively (see Fig. $3 B$ ). Throughout all experiments, input resistance and series resistance were monitored with a $-10 \mathrm{mV}, 250 \mathrm{msec}$ voltage pulse. Paired-pulse stimuli at $30-50 \mathrm{msec}$ intervals were delivered to test for possible involvement of presynaptic sites of action. In some cases, postsynaptic NMDA receptor function was assessed directly by picoliter pressure application of NMDA (Tocris) with a Pressure System IIe (Toohey Company, Fairfield, NJ). In these experiments, signals were low-pass filtered at a cutoff frequency of $1-3 \mathrm{kHz}$ and digitized at twice the filter frequency. Other drugs used include R-(+)-SKF-38393 hydrochloride, forskolin, 1,9-dideoxyforskolin, (R)(+)-SCH-23390 hydrochloride, DA (Sigma), sulpiride, Rp-cAMPS, 3-aminopropyl diethoxymethyl phosphinic acid (CGP35348), N-(piperidin-1-yl)-5-(4iodophenyl)-1-(2,4-dichlorophenyl)-4-methyl-1H-pyrazole-3-carboxamide (AM251), 8-cyclopentyl-1,3-dipropylxanthine (DPCPX), 6-cyano-7-nitroquinoxaline-2,3-dione (CNQX), and $\mathrm{D}(-)$-2-amino-5-phosphonopentanoic acid (D-APV) (Tocris). Forskolin, sulpiride, DPCPX, and AM251 stock solutions were prepared in dimethyl sulfoxide (DMSO; Fisher Scientific, Fair Lawn, NJ). Stock solutions of 1,9-dideoxyforskolin and SCH-23390 were prepared in 100\% ethanol. CNQX was first dissolved in $0.1 \mathrm{~N} \mathrm{NaOH}$ or DMSO. Other stock solutions were prepared in deionized water. Unless specified otherwise, all drugs were diluted 1:1000 in picrotoxin-containing ACSF and bath applied.

Data analysis. To quantify the ramp response, the linear portion of the response curve (i.e., the portion mediated by passive conductance) was first estimated by averaging data points between 100 and $150 \mathrm{msec}$ after the onset of the ramp. The ramp index was computed as the charge under the curve between the onset of the ramp and $400 \mathrm{msec}$ after, from which the linear portion was deducted. Intuitively, the ramp index captures the balance between inward and outward currents mediated by voltage-dependent conductances.

In most cases, the size of non-NMDA receptor-mediated EPSCs (EPSC size) was measured at the minimum point after the stimulus. In experiments in which drug application reduced the EPSC such that the stimulus artifact prevented identification of the minimum point, we measured the latency to the minimum point from traces recorded before drug application. We then measured EPSC size using a $1 \mathrm{msec}$ window average at this latency for all traces. The size of NMDA receptormediated EPSCs (late EPSC size) was measured at 29-49 msec after stimulus onset, depending on the presence/interval of a subsequent stimulus pulse (see Fig. 3B). A constant latency was used for each experiment. In cases in which a pulse pair was delivered, the second late EPSC size was measured as the difference between the absolute current value at the specified latency and the value extrapolated from the first EPSC using a single-exponential fit. Paired-pulse ratio was calculated as the ratio of the second EPSC size to the first. The percentage change induced by drug application was calculated as (value with drug - value before drug)/value before drug, expressed in percentage, in which each value was an average from 10 iterations in most experiments. "Value before drug" was measured immediately before the onset of drug entry. "Value with drug" was measured 7-10 min after the onset of drug entry. In experiments using pressure application of NMDA, the peak amplitude of response to each puff was measured. The percentage change was calculated as described above except that only three to five values were averaged. This is because the response to NMDA puff was substantially longer than that to electrical stimulation, which led to fewer samples within the same sampling period. Experiments were excluded from further analysis if there was $>20 \%$ increase in the series resistance. Also excluded were cells with unstable responses before drug applications. Statistical results were obtained using internal functions in Prism 3.0 (GraphPad Software Inc., San Diego, CA). For multiple comparisons of the percentage change in 
EPSC size, the Kruskal-Wallis test was used, followed by Dunn's multiple comparison test. Each example trace is an average of five consecutive raw traces, unless specified otherwise.

Histological procedures. After an experiment was completed, the slice was fixed in paraformaldehyde ( $4 \%$ in $0.1 \mathrm{~m}$ phosphate buffer) overnight at $4^{\circ} \mathrm{C}$ and transferred to a sucrose solution (30\% sucrose in $0.1 \mathrm{M}$ phosphate buffer) for cryoprotection. After at least overnight immersion in the sucrose solution at $4^{\circ} \mathrm{C}$, slices were sectioned to $50 \mu \mathrm{m}$ thickness with a freezing microtome. Resectioned slices were processed with an avidinbiotin-horseradish peroxidase complex kit, Vector ABC Elite Kit, followed by a reaction with either the Vector VIP peroxidase substrate kit (Vector Laboratories, Burlingame, CA) or diaminobenzadine. Labeled neurons were inspected using $40 \times$ and $100 \times$ objectives for characteristic morphological features of different cell types described previously by Farries and Perkel (2002). Soma area of each recovered neuron was measured, from which soma diameter was estimated assuming a spherical cell body.

\section{Results}

Brain slices from 48 adult male zebra finches were used. On the basis of criteria described in Materials and Methods (Fig. 1), we were able to distinguish SNs from other cell types in area X. Examples of an $\mathrm{SN}$ and a non-SN type neuron are shown in Figure 2, $A$ and $B$, respectively. The initial resting potentials were -70 and $-63 \mathrm{mV}$, respectively. In response to the standard voltage ramp, putative SNs showed a distinct large inward current, peaking first at approximately $-30 \mathrm{mV}$ and then again during the hyperpolarizing phase of the ramp (Fig. $2 A$, inset). Non-SNs responded with mostly outward current and occasional inward inflections (Fig. $2 B$, inset). When we plotted the ramp index against the initial resting potential for all cells that we encountered, two clusters formed: one with more hyperpolarized initial resting potentials and negative ramp indices, and one with more depolarized initial resting potentials and positive ramp indices (Fig. $2 C)$. Spontaneously active neurons appeared exclusively in the latter cluster. The ratio of number of cells located in each cluster is consistent with the high density of SNs and sparse distribution of cells of other types in area X (Farries and Perkel, 2002). When recovered histologically, cells from the first cluster had smaller soma diameters than those from the second cluster (Fig. 2D). In addition, spiny dendrites were found exclusively on cells from the first cluster. We thus consider the first cluster as representing the $\mathrm{SN}$ class. In this paper, only cells $(n=59)$ located within the first cluster, i.e., with negative ramp indices, were used (Fig. 2C, filled circles).

To separate inputs from HVC and LMAN, we stimulated fibers as shown in Figure $3 A$. The summary of stimulation sites is shown in Table 1. The phenomena that we observed, as described below, do not seem to depend on particular sites of stimulation. We therefore do not distinguish HVC or LMAN inputs to area $\mathrm{X}$ in this paper.

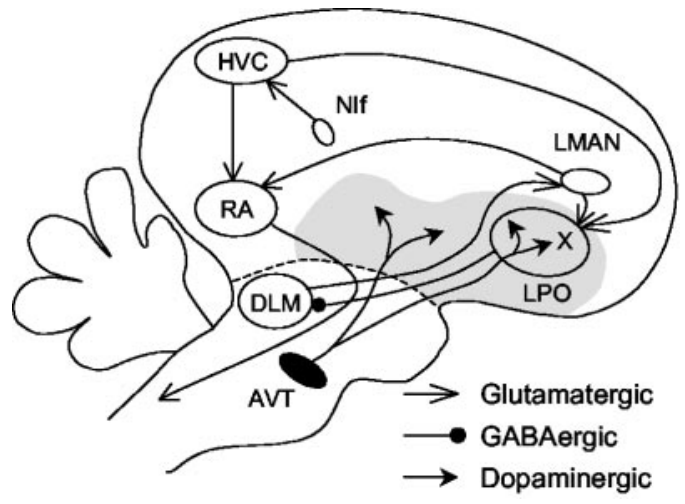

Figure 1. A simplified diagram of the oscine song system. The song system consists of three major pathways. The nucleus interfacialis (NIf) likely provides key auditory input to the song system. The motor pathway starts with nucleus HVC (used as a proper name). HVC projects to the robust nucleus of archistriatum (RA), which innervates several brainstem nuclei controlling respiration and vocalization. The anterior forebrain pathway starts with the projection from HVC to area $X$, a part of the avian basal ganglia within the lobus parolfactorius (LPO). Area X projects to the medial portion of the dorsolateral nucleus of the anterior thalamus (DLM), which sends its output to the lateral magnocellular nucleus of the anterior neostriatum (LMAN), which projects to $R A$ and sends collaterals to area $X$. Area $X$ thus receives glutamatergic inputs from HVC and LMAN. It also receives dense dopaminergic inputs from the ventral area of Tsai (AVT). The gray area represents the paleostriatal complex.
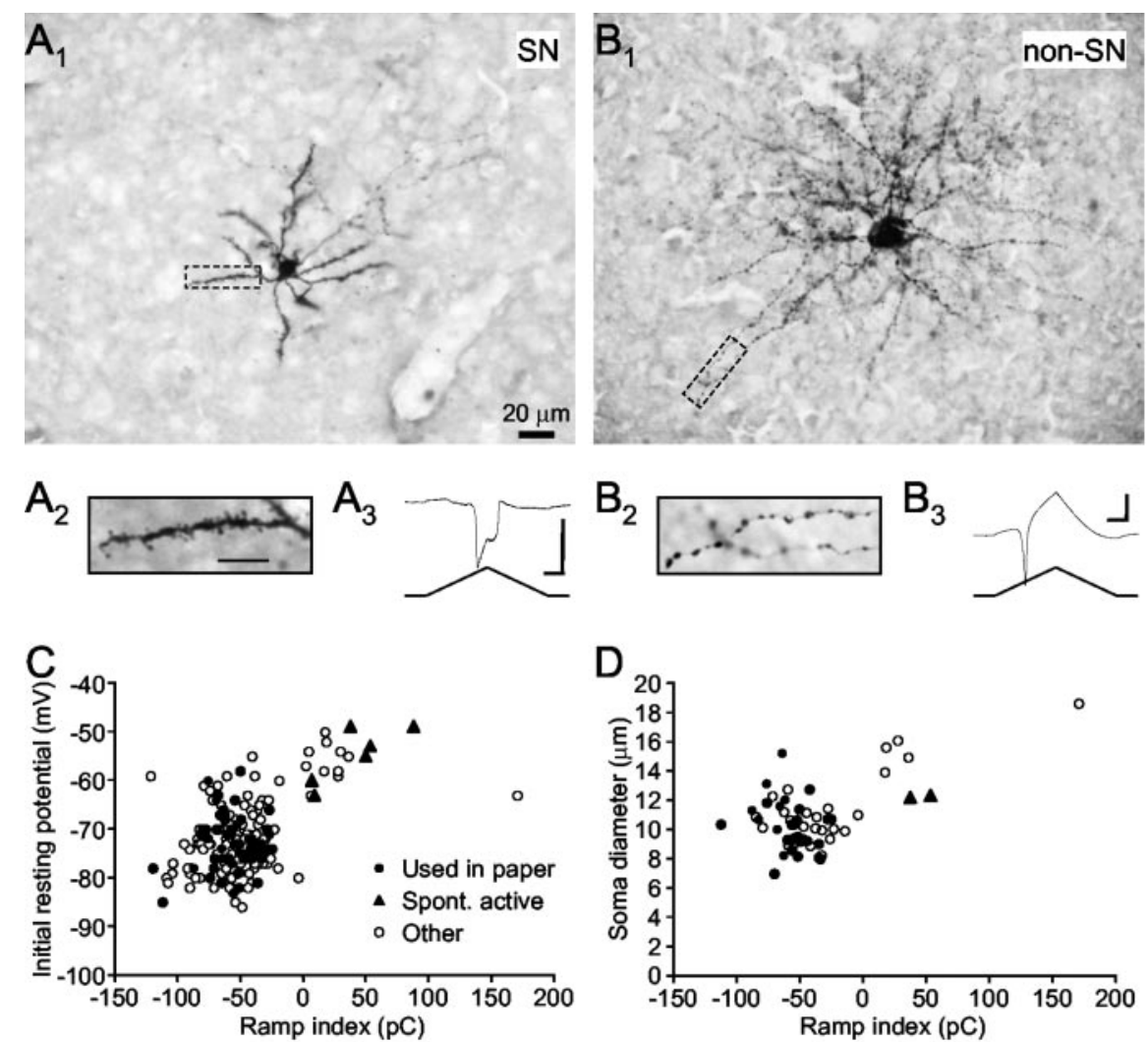

Figure 2. Classification of spiny versus nonspiny neurons in area X. $A_{1}$, A micrograph of a spiny neuron recovered histologically after recording. Scale bar, $20 \mu \mathrm{m}$. $A_{2}$, A spiny dendrite of the same cell viewed at higher magnification. Scale bar, $10 \mu \mathrm{m}$. $A_{3}$, The response of this cell to the standard voltage ramp. Note the prominent double-peaked inward current. Calibration: vertical $500 \mathrm{pA}$, horizontal $100 \mathrm{msec} . B_{1}$, A micrograph of a nonspiny neuron; same scale as $A_{1}$. Note the larger soma and different shape of dendritic branches, compared with $A_{1}$. $B_{2}$, The dendrite of this cell is beady but not spiny; same scale as $A_{2}$. $B_{3}$, The ramp response. Note the large outward current after the early inward peak. Calibration: vertical 500 pA, horizontal $100 \mathrm{msec}$. C, Scatter-plot of the initial resting potential and ramp index calculated from the ramp response. Filled circles represent cells used in this paper; filled triangles represent cells that were spontaneously active before patching; open circles represent other cells recorded. Note the two distinct clusters and the large proportion of cells in the left cluster. D, Scatter-plot of the soma diameter and ramp index from all cells reconstructed histologically. 


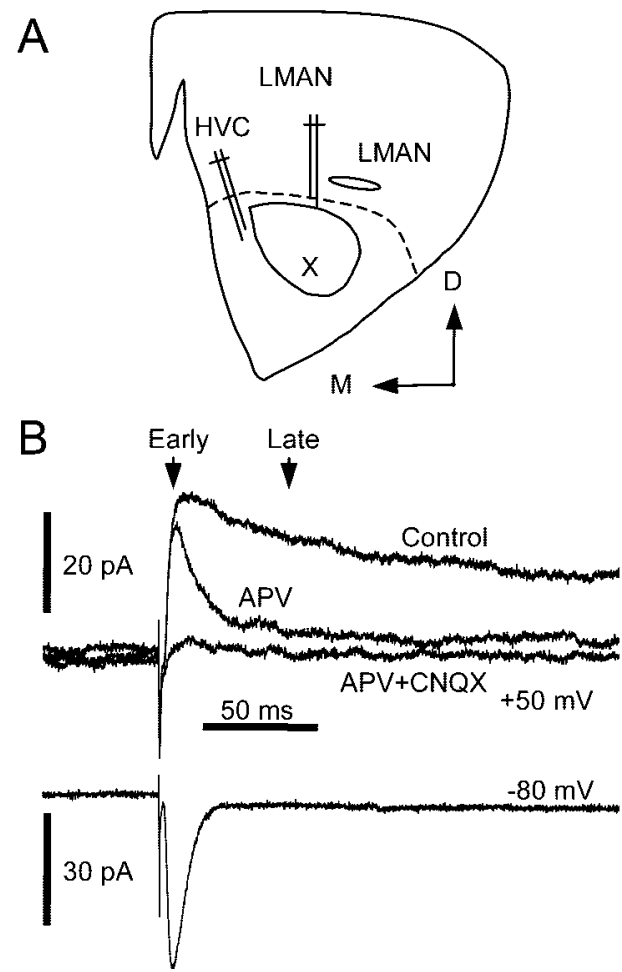

Figure 3. A, Illustration of a coronal section through area $X$ and placement of stimulating electrodes. $B$, Pharmacological and temporal isolation of NMDA and non-NMDA receptormediated EPSCs. EPSCs were evoked at holding potentials of +50 and $-80 \mathrm{mV}$. Arrows indicate the time points when early and late components of the EPSC were measured.

Table 1. Summary of stimulation sites

\begin{tabular}{lrllr}
\hline & $n$ & HVC & LMAN & X \\
\hline SKF (non-NMDA) & 8 & 2 & 1 & 5 \\
SKF (NMDA) & 20 & 3 & 8 & 9 \\
FSK (non-NMDA) & 9 & 4 & 3 & 2 \\
FSK (NMDA) & 23 & 3 & 6 & 14 \\
\hline
\end{tabular}

Note: The number for FSK (NMDA) includes experiments at both negative and positive holding potentials.

As described previously (Farries, 2002), at a positive holding potential, the late component of the EPSC was abolished by 50 $\mu \mathrm{M}$ APV (Figs. $3 B, 9 D)(n=11$; percentage reduction: $90 \pm$ $10 \%)$. The remaining early component and EPSCs evoked at -80 $\mathrm{mV}$ were blocked by $10 \mu \mathrm{M}$ CNQX (Fig. $3 B)(n=19$; percentage reduction: $93 \pm 6 \%$ ). Thus, the EPSC evoked at $-80 \mathrm{mV}$ is mediated primarily by non-NMDA receptors, whereas the late component of the EPSC evoked at positive potentials is mediated primarily by NMDA receptors.

We found that SKF-38393, a D1-like DA receptor agonist, reduced both non-NMDA and NMDA receptor-mediated EPSCs (Fig. 4). At a holding potential of $-80 \mathrm{mV}, 10 \mu \mathrm{M}$ SKF-38393 caused a small but significant decrease in the peak EPSC (Fig. 4A) $(n=8$; two-tailed Wilcoxon ranked test; $p=0.039)$ (Table 2). At positive holding potentials, SKF-38393 significantly and reversibly reduced the peak as well as the late component of EPSCs (Fig. $4 B)(n=20$ for the late component; two-tailed Wilcoxon ranked test; $p=0.0002$ ) (Table 2 ) and the waveform scaled similarly, suggesting that both non-NMDA and NMDA receptor-mediated components were affected. The percentage change in EPSC size is comparable for non-NMDA and NMDA receptor-mediated components (Dunn's multiple comparison test; $p>0.05$ ). There was no significant change in input resistance measured at either
$-80 \mathrm{mV}$ or positive holding potentials (two-tailed Wilcoxon ranked test; $p=0.5625$ and 0.2397 , respectively).

To test whether the observed effects were mediated by activation of D1-like DA receptors, we applied SKF-38393 after a 10 min preincubation of SCH-23390, a D1-like DA receptor antagonist. Because the reduction in non-NMDA and NMDA receptor-mediated components seemed to be concurrent, we tested the effect of SCH-23390 on EPSCs recorded at positive holding potentials and focused on the NMDA receptor-mediated EPSC. We found that preincubation of SCH-23390 (10-20 $\mu \mathrm{M})$ blocked the effect of SKF-38393 (Fig. 4C) ( $n=5$; Dunn's multiple comparison test; $p<0.01$ ) (Table 2). In contrast, preincubation of sulpiride $(10 \mu \mathrm{M})$, a D2-like DA receptor antagonist, failed to block the effect of SKF-38393 (Fig. $4 C)$ ( $n=3$; Dunn's multiple comparison test; $p>0.05$ ). These results suggest that SKF38393 suppresses NMDA receptor-mediated EPSCs by activating D1-like DA receptors.

D1-like DA receptor activation triggers a G-protein-mediated signal cascade that stimulates adenylyl cyclase and subsequently PKA (Memo et al., 1986). We next tested whether this pathway was involved in inducing the effects of SKF-38393. We first examined whether forskolin, a potent membrane-permeable adenylyl cyclase activator, could mimic the depressing effects of SKF-38393. We found that forskolin dramatically reduced both the non-NMDA and NMDA receptor-mediated EPSCs (Fig. 5). At a holding potential of $-80 \mathrm{mV}, 10 \mu \mathrm{M}$ forskolin reversibly reduced peak EPSC amplitude (Fig. $5 A, C)(n=9$; two-tailed Wilcoxon rank test; $p=0.0039$ ) (Table 2 ). At a positive holding potential, forskolin also reversibly decreased the size of the late component of EPSCs (Fig. $5 B, C)(n=18$; two-tailed Wilcoxon rank test; $p=0.0002$ ) (Table 2). Similar effects were also observed on the late EPSC size at negative holding potentials (Fig. 5C) $(n=$ 5 ), suggesting that the reduction is not voltage dependent. The extent of the reduction is comparable for non-NMDA and NMDA receptor-mediated components (Dunn's multiple comparison test; $p>0.05$ ). There was no significant change in input resistance measured at either $-80 \mathrm{mV}$ or positive holding potentials (two-tailed Wilcoxon ranked test; $p=0.4375$ and 0.5417 , respectively). The depression was not observed with application of $0.1 \%$ DMSO alone ( $n=3$; data not shown), confirming that it results from actions of forskolin itself.

Forskolin has multiple effects on cellular properties, including stimulating adenylyl cyclase activity (Laurenza et al., 1989). To test whether the observed effects of forskolin indeed depended on adenylyl cyclase activity, we performed similar experiments using 1,9-dideoxyforskolin, an inactive forskolin analog that does not stimulate adenylyl cyclase. We found that 1,9-dideoxyforskolin $(10 \mu \mathrm{M})$ failed to change the EPSCs, even in cells in which subsequent forskolin application induced a significant reduction (Figs. $6 A, C)(n=5$; Dunn's multiple comparison test; $p<0.001)$ (Table 2). Furthermore, 10 min preincubation in $10 \mu \mathrm{M} \mathrm{Rp}-$ cAMPS, a membrane-permeable inhibitor of cAMP-dependent protein kinase activity, prevented the forskolin-induced suppression of EPSCs (Fig. 6B, $C)(n=7$; Dunn's multiple comparison test; $p<0.001$ ) (Table 2). These results indicate that forskolin reduces the EPSC by stimulating adenylyl cyclase activity and subsequently activating the PKA pathway. We next tested whether the PKA pathway also mediates the effect of SKF-38393. We found that preincubation in Rp-cAMPS also blocked the SKF-38393-induced reduction in EPSCs measured at positive holding potentials (Fig. $6 C, D)(n=11$; Dunn's multiple comparison test; $p<0.01)$. Thus, SKF-38393 application reduces EPSCs by activating D1-like DA receptors and the PKA pathway. 
These effects could be mediated presynaptically or postsynaptically, or both. Activation of postsynaptic D1-like DA receptors enhances excitability in SNs in area $\mathrm{X}$ in zebra finches (Ding and Perkel, 2002). Postsynaptic D1-like DA receptors could also mediate the effects of SKF-38393 on EPSCs. Alternatively, given that both nonNMDA and NMDA receptor-mediated responses were affected, a presynaptic modulation of synaptic transmission is also conceivable. Because the PKA pathway is required for the effects of SKF-38393, we chose to probe the two possibilities with forskolin, because it is much more potent in activating the PKA pathway. Positive findings obtained from forskolin were followed using SKF-38393 to test whether similar conclusions could be drawn for activation of D1-like DA receptors.

We first tested whether the reduction in EPSC is attributed to presynaptic depression of transmitter release. A commonly used indicator for a reduction in presynaptic transmitter release is an increase in the paired-pulse ratio (Manabe et al., 1993). We found that forskolin raised the pairedpulse ratio (Fig. 7A) (two-tailed Wilcoxon rank test; $p=0.0078$; also see example traces 2 and 3 in Fig. 6A). Another indication for a reduction in transmitter release is an increase in coefficient of variation (CV) of the synaptic current amplitude (del Castillo and Katz, 1954; Malinow and Tsien, 1990), which we also observed with forskolin application (Fig. 7B) (two-tailed Wilcoxon rank test; $p<0.0001$ ). Thus, both measurements of paired-pulse ratio and CV suggest that forskolin decreases presynaptic transmitter release. To test whether the same held for activation of D1-like DA receptors, we analyzed paired-pulse ratio and CV values of NMDA receptor-mediated EPSCs with SKF-38393 application. As with forskolin, SKF38393 also significantly increased paired-pulse ratio and CV (Fig. $7 C, D)(n=11$ and $20, p=0.042$ and 0.0014 , respectively), suggesting that activation of D1-like DA receptors reduces the EPSC by decreasing presynaptic transmitter release. An additional commonly used test for involvement of a presynaptic site of action is through analysis of spontaneous EPSCs; we were unable to perform this test because area X SNs receive very few spontaneous EPSCs.

To test whether postsynaptic mechanisms were also involved, we made recordings with internal solutions containing 100-400 $\mu \mathrm{M}$ Rp-cAMPS. We have shown that bath-applied $10 \mu \mathrm{M}$ RpcAMPS blocks the effects of forskolin and SKF-38393 (Fig. 6). If intracellularly applied Rp-cAMPS blocked or reduced these effects, then postsynaptic PKA-mediated mechanisms must contribute to the overall reduction in EPSCs. If the effects of forskolin and SKF-38393 were augmented instead, then activation of the postsynaptic mechanisms alone may actually enhance EPSCs. Alternatively, if forskolin and SKF-38393 continued to cause normal depression, they likely act only at presynaptic sites. We tested our predictions on the NMDA receptor-mediated EPSCs in six cells $>20$ min after the initial access was obtained. Our results support the last prediction: intracellular Rp-cAMPS did not alter
Table 2. Percentage change in EPSC size

\begin{tabular}{|c|c|c|c|c|}
\hline & $n$ & Minimum & Medium & Maximum \\
\hline SKF (non-NMDA) & 8 & -27 & -8 & 2 \\
\hline SKF (NMDA) & 20 & -81 & -20 & 11 \\
\hline SKF + SCH (NMDA) & 5 & -1 & 1 & 22 \\
\hline SKF + Rp-cAMPS ${ }_{E X}(N M D A)$ & 11 & -20 & -2 & 29 \\
\hline SKF + Rp-CAMPS ${ }_{\text {IN }}(\mathrm{NMDA})$ & 5 & -45 & -16 & -5 \\
\hline SKF + Sulpiride (NMDA) & 3 & -36 & -33 & -21 \\
\hline FSK + AM251 (non-NMDA) & 3 & -36 & -58 & -59 \\
\hline FSK + DPCPX (non-NMDA) & 5 & -4 & 12 & 38 \\
\hline FSK (non-NMDA) & 9 & -65 & -44 & -31 \\
\hline FSK (NMDA) & 18 & -85 & -48 & -27 \\
\hline DDF (NMDA) & 5 & -8 & 5 & 17 \\
\hline$F S K+R p-c A M P S_{E X}(N M D A)$ & 7 & -25 & -1 & 40 \\
\hline FSK + Rp-CAMPS & 4 & -70 & -52 & -35 \\
\hline FSK (Puff NMDA) & 6 & -20 & 3 & 10 \\
\hline FSK + CGP35348 (NMDA) & 2 & -25 & & -52 \\
\hline
\end{tabular}

Note: The number for FSK (NMDA) includes experiments at positive holding potentials alone.

the forskolin- or SKF-38393-induced depression of the EPSCs (Fig. 8). In the presence of intracellular Rp-cAMPS, forskolin reduced the late component of the EPSC by an average of $52 \%$ (Fig. $8 A, B$, Table 1) $(n=4)$, whereas SKF-38393 reduced it by $16 \%$ (Fig. $8 C, D$, Table 1) $(n=5)$. The percentage changes induced by forskolin or SKF38393 were not different from those in the absence of intracellular Rp-cAMPS (Dunn's multiple comparison tests; $p>0.05$ for both forskolin and SKF-38393), which is consistent with purely presynaptic modulation by forskolin and SKF-38393.

To explore further whether postsynaptic mechanisms contribute to forskolin and D1-like DA receptor activation-induced 

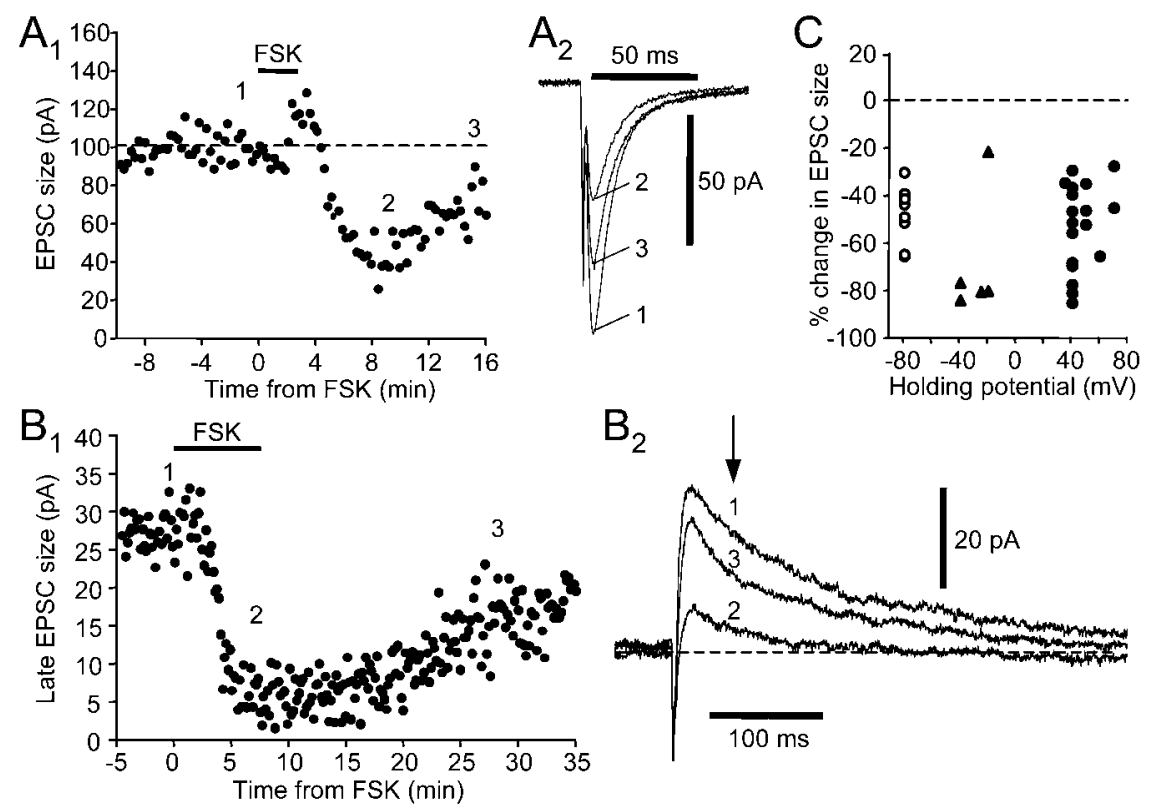

Figure 5. Forskolin (FSK; $10 \mu \mathrm{M}$ ) mimics the synaptic depression induced by SKF-38393. $A_{1}$, FSK reversibly reduced the amplitude of the non-NMDA receptor-mediated EPSC. The numbers indicate the time when example traces in $A_{2}$ were taken. $A_{2}$, Example traces. Holding potential was $-80 \mathrm{mV}$. $B_{1}$, FSK reversibly reduced the size of the NMDA receptor-mediated late component of the EPSC. $B_{2}$, Example traces. Holding potential was $+40 \mathrm{mV}$. C, A similar depressing effect of FSK was observed at various holding potentials, as shown in the summary plot of FSK-induced percentage change in EPSC size. Open circles represent nonNMDA receptor-mediated component measured at a holding potential of $-80 \mathrm{mV}$; filled triangles represent NMDA receptormediated component measured at negative holding potentials between -40 and $-20 \mathrm{mV}$; filled circles represent NMDA receptor-mediated component measured at positive holding potentials between +35 and $+70 \mathrm{mV}$. reduction in the EPSC, we next probed NMDA receptor function directly with pressure application of NMDA (2-100 $\mathrm{mM}$ ) and examined whether forskolin reduces the response to NMDA. The current-response to pressure-applied NMDA ("puffing") had the same voltage dependence as the late component of EPSCs evoked electrically (Figs. 9A,B) (note similar enhanced responses at approximately $-20 \mathrm{mV}$ and the same reversal potential for all responses). They also had similar sensitivity to APV (Fig. 9D), confirming that the puff response was mediated by NMDA receptors. In all six cells tested, forskolin failed to reduce responses to the NMDA puff (Fig. 9C) (two-tailed Wilcoxon signed rank test; $p=0.8438$ ). The percentage change in puff response ranged from -20 to $10 \%$, with a median value of $3 \%$, significantly different from the percentage change in EPSC size (Dunn's multiple comparison test; $p<0.001)$. Furthermore, in two cells, puffs and electrical stimuli were interleaved during the same forskolin application (Fig. 9C, filled symbols). In the cell shown in Figure 9D, forskolin had no effect on the puff response during its application, whereas it signifi-
A

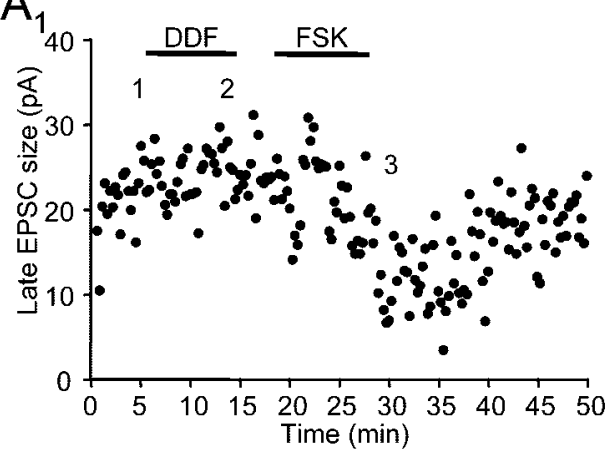

$\mathrm{A}_{2}$

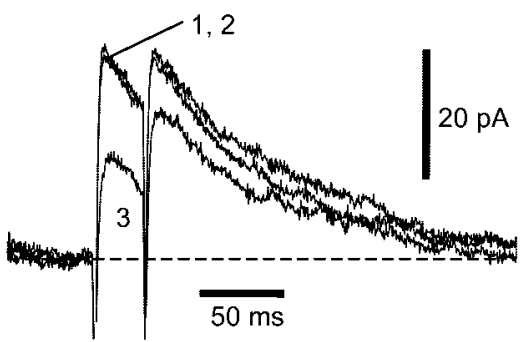

$\mathrm{C}_{2}$

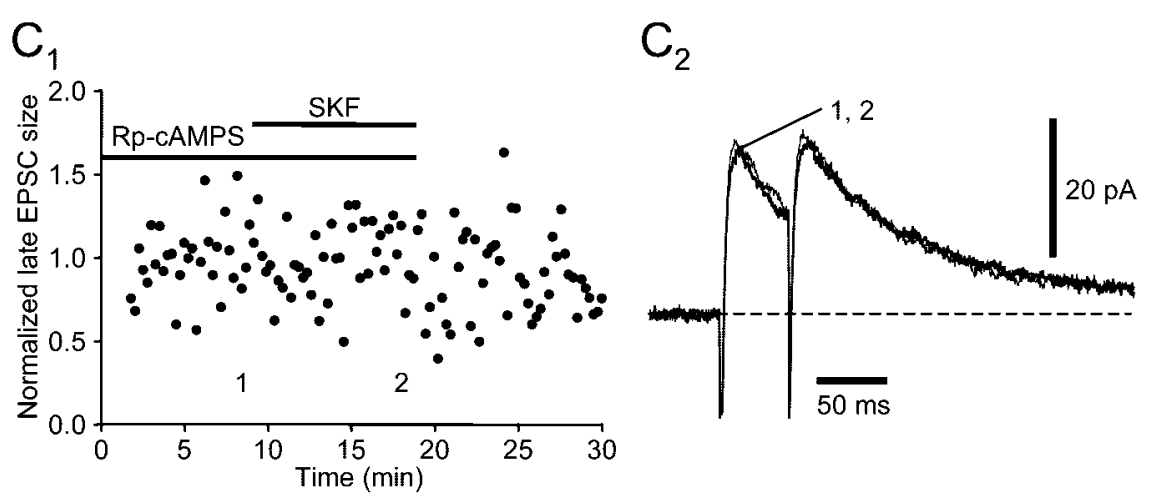

B

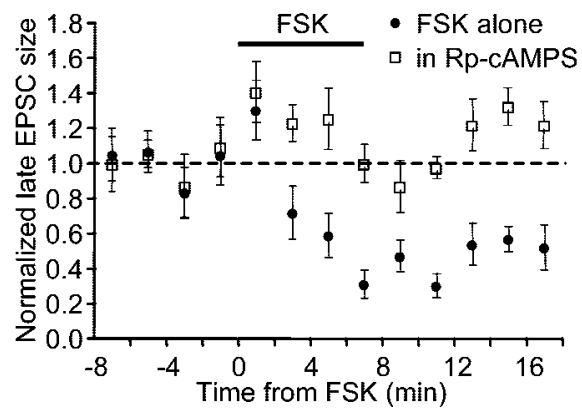

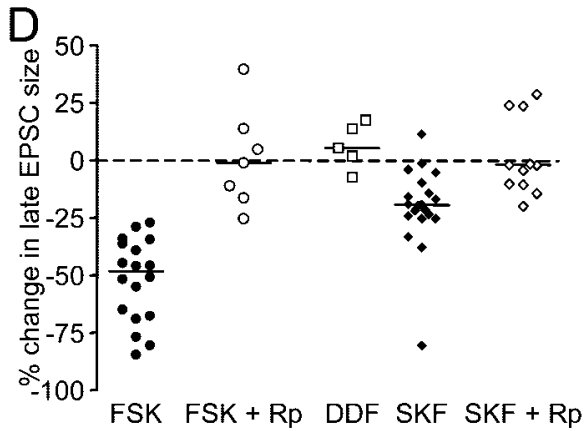

Figure 6. The effects of SKF-38393 and forskolin are both mediated by the adenylyl cyclase-PKA pathway. $A_{1}, 1,9$-dideoxyforskolin (DDF) failed to reduce the size of the NMDA receptor-mediated late component of the EPSC, but forskolin (FSK) did reduce this component. The numbers indicate the time when example traces in $A_{2}$ were taken. $A_{2}$, Example traces. Holding potential was $+40 \mathrm{mV}$. $B$, Bath-applied Rp-CAMPS $(10 \mu \mathrm{M})$ blocked the effect offorskolin. Each symbol represents the mean \pm SEM of late EPSC size in a 2 min window normalized to the value before forskolin application. All data are from the same cell. Filled circles represent forskolin application in the absence of Rp-CAMPS; open squares represent subsequent forskolin application in the presence of Rp-cAMPS after a 10 min preincubation in Rp-cAMPS. $C_{1}$, Bath-applied Rp-CAMPS $(10 \mu \mathrm{m})$ blocked the effect of SKF-38393. The numbers indicate the time when example traces in $C_{2}$ were taken. $C_{2}$, Example traces. Holding potential was $+40 \mathrm{mV}$. ${ }_{\text {, }}$ Summary plot of forskolin or SKF-38393-induced change in late EPSC size measured at positive holding potentials between +30 and $+70 \mathrm{mV}$. 
cantly reduced the EPSC size during the same period. This is in clear contrast to the APV-induced parallel decrease in both the EPSC size and puff response. Thus, forskolin does not seem to suppress postsynaptic NMDA receptor functions.

Taken together, these data suggest that the SKF-38393 and forskolin-induced depression in EPSCs is mediated by a presynaptic site of action. Presynaptic depression could result from activation of presynaptic D1-like DA receptors or, alternatively, from actions of a diffusible messenger released in response to SKF-38393 or forskolin. We next tested whether adenosine, GABA, or endocannabinoids could serve as such a messenger, as reported at other glutamatergic synapses (Dolphin and Prestwich, 1985; Dunwiddie and Haas, 1985; Dutar and Nicoll, 1988; Shen et al., 1996). We found that preincubation of 500 nM DPCPX, an adenosine A1 receptor antagonist, completely abolished the depressing effect of forskolin (Fig. 10A,B) ( $n=5$; Dunn's multiple comparison test; $p<0.01$ ), whereas $500 \mu \mathrm{M}$ CGP-35348, a $\mathrm{GABA}_{\mathrm{B}}$ receptor antagonist, or $4-5 \mu \mathrm{M}$ AM-251, a cannabinoid CB1 receptor antagonist, had no effect (Fig. $10 B)(n=2$ and 3, respectively), suggesting that activation of adenosine receptors mediates forskolin-induced presynaptic depression.
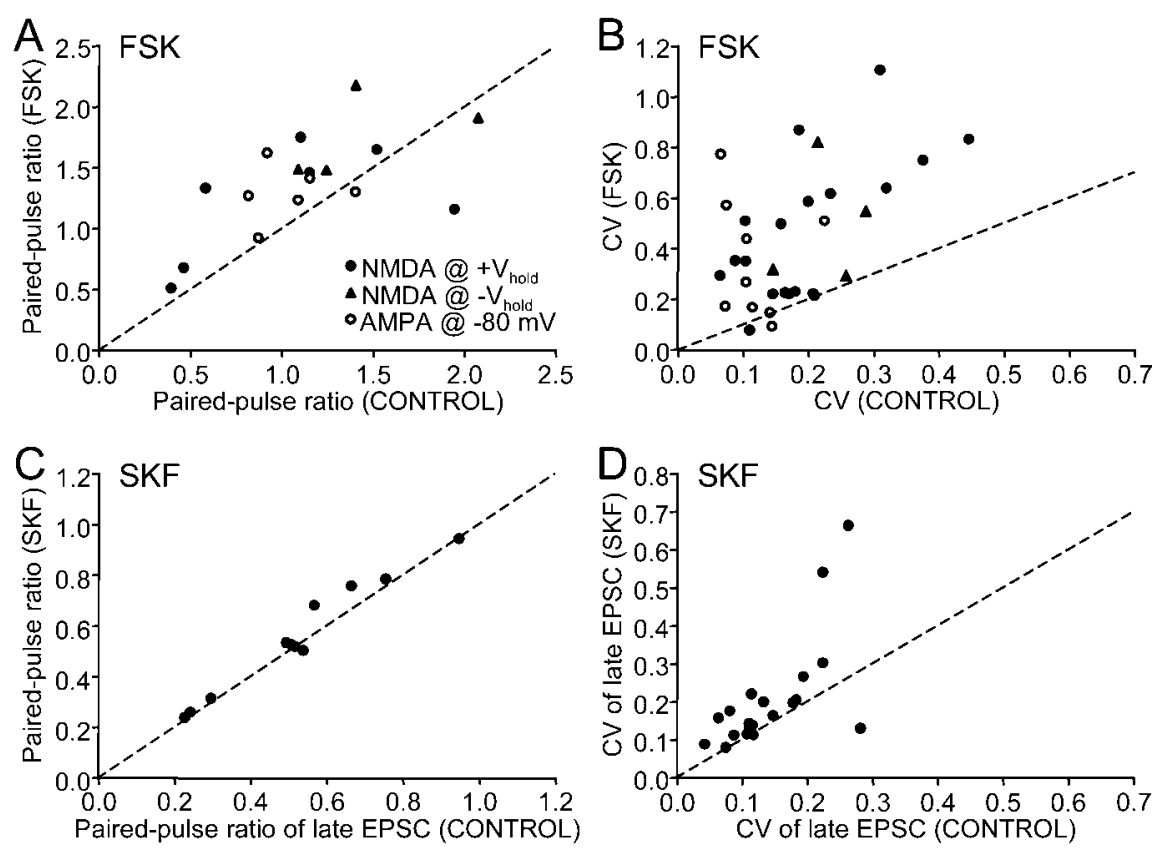

Figure 7. Paired-pulse ratio and coefficient of variation of EPSC amplitude increased in the presence of forskolin $(A, B)$ and SKF-38393 (C, D). A, C, Scatter-plot of paired-pulse ratios before and during forskolin and SKF-38393 application, respectively. Filled circles represent values measured from late EPSC size at positive holding potentials; filled triangles represent values from late EPSC size at negative holding potentials; open circles represent values from EPSC amplitude at $-80 \mathrm{mV}$; dashed line represents a line with a slope of 1 . Note that most data points lie above the line, indicating an increase in paired-pulse ratio in the presence of forskolin/SKF-38393. B, D, Scatter-plot of coefficients of variation before and during forskolin and SKF-38393 application, respectively. Note that most data points lie above the line.

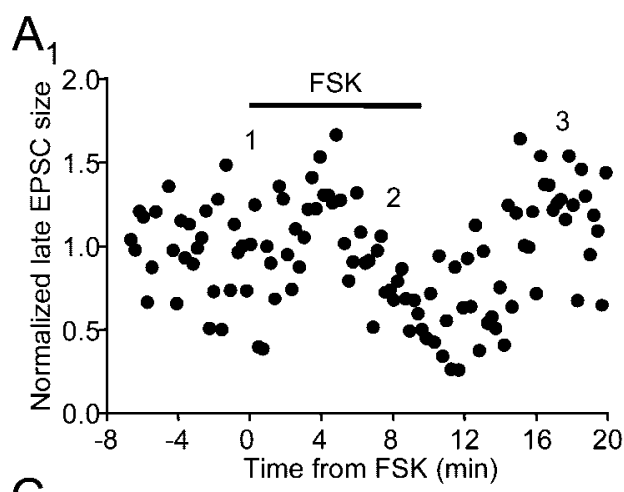

$\mathrm{C}_{1}$

$\mathrm{A}_{2}$

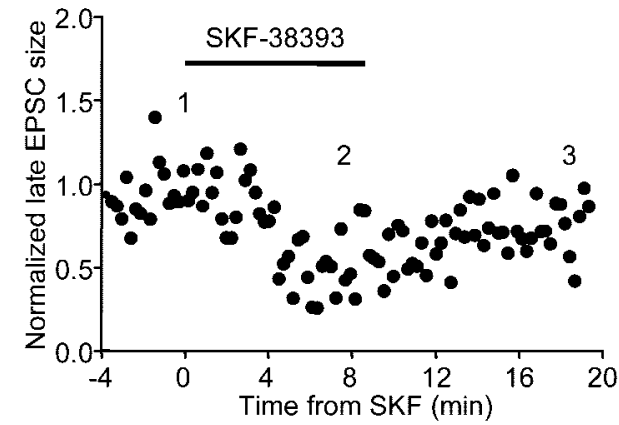

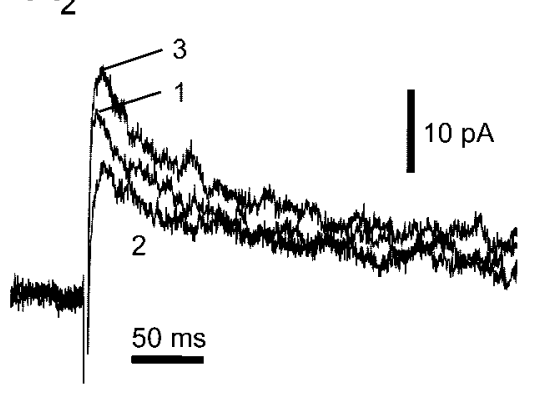

$\mathrm{C}_{2}$

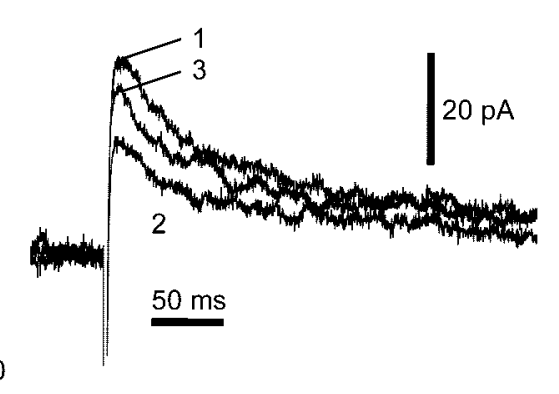

$\mathrm{B}$

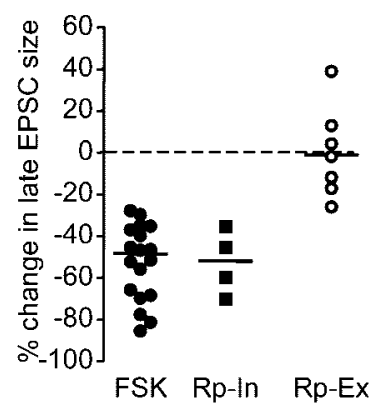

$\mathrm{D}$

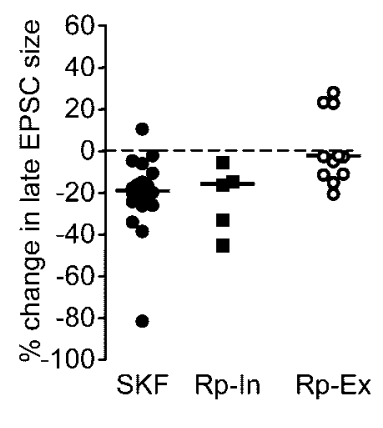

Figure 8. Intracellularly applied Rp-CAMPS $(100-400 \mu \mathrm{m})$ does not block the effects of forskolin and SKF-38393. $A_{1}$, Forskolin reduced the late EPSC size in the presence of intracellular Rp-cAMPS. $A_{2}$, Example traces. Holding potential was $+40 \mathrm{mV}$. B, Summary plot of change induced by forskolin. Rp-In, Forskolin application in the presence of intracellularly applied Rp-cAMPS; Rp-Ex, forskolin application in the presence of bath-applied Rp-cAMPS. $C_{1}$, In the same cell as in $A$, SKF-38393 also reduced the late EPSC size in the presence of intracellular Rp-CAMPS. $C_{2}$, Example traces. Holding potential was $+40 \mathrm{mV}$. D, Summary plot of percentage change induced by SKF-38393. Horizontal lines indicate median values. 

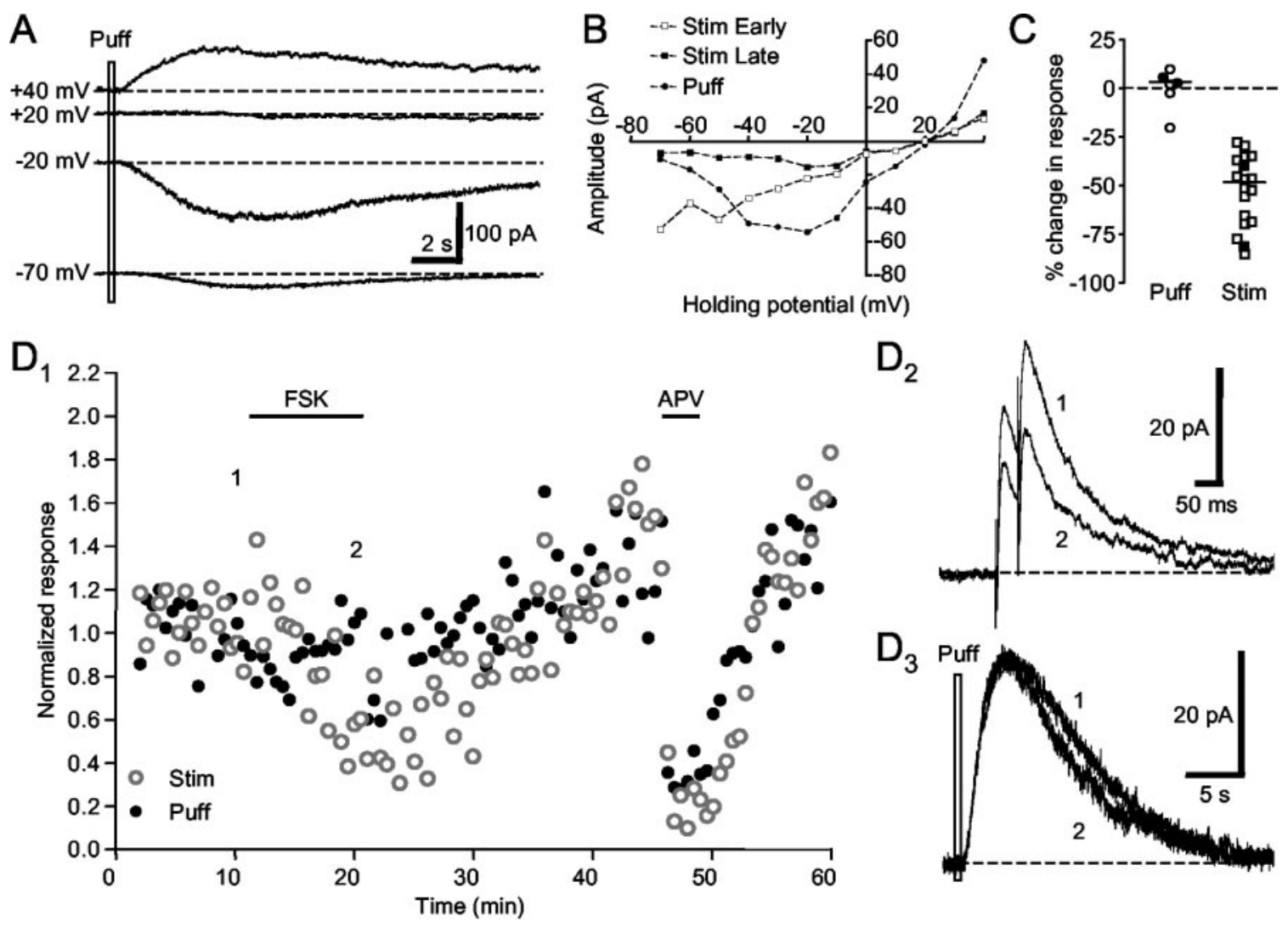

Figure 9. Forskolin does not reduce postsynaptic NMDA receptor function. $A$, Direct pressure application of NMDA ( $2 \mathrm{~mm})$ induced voltage-sensitive current responses (puff response) in a spiny neuron. Note the reversal potential at approximately $+20 \mathrm{mV}$. B, In the same cell shown in $A$, the current-voltage plot of the puff response showed voltage dependence similar to that of the late component of the EPSC evoked with electrical stimulation. C, Summary plot of the change in the puff response and the late component of the EPSC by forskolin application. Filled symbols represent two cells where puffs and electrical stimulation were interleaved, one of which is shown in $D . D_{1}$, Forskolin reduced the EPSC but not the puff response in a spiny neuron. Subsequent application of APV blocked both the late component of EPSC and the puff response. $D_{2}$, Example traces of the EPSC. $D_{3}$, Example traces of the puff response. Holding potential was $+40 \mathrm{mV}$.
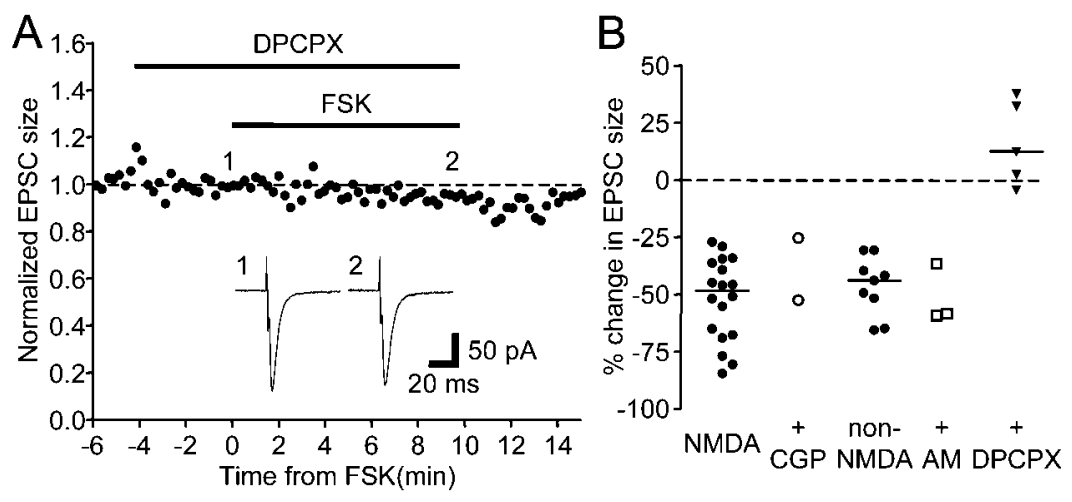

Figure 10. A, The adenosine A1 receptor antagonist DPCPX (500 nm) blocked forskolin-induced synaptic depression. Inset, Example traces of EPSCS. Holding potential was $-80 \mathrm{mV}$. B, Summary plot of the change in EPSC size by forskolin application in the presence of (GP35348 (CGP; $500 \mu \mathrm{m}$ ), AM251 (AM; 4-5 $\mu \mathrm{M}$ ), or DPCPX (500 nM). Data points labeled "NMDA" and "CGP" were measured from the late component of EPSCS at positive holding potentials, whereas the others were from EPSC sizes recorded at a holding potential of $-80 \mathrm{mV}$.

In a small subset of cells, we also observed a much-delayed potentiation (Fig. 11) ( $n=3$ of 11). In the example shown in Figure 9D, an enhancement of both the EPSC size and puff response developed $\sim 25$ min after forskolin was washed out of the bath. This suggests that forskolin may trigger delayed potentiation of postsynaptic NMDA receptor functions. However, given the infrequent occurrence of this phenomenon, we did not pursue it further in this study.

\section{Discussion}

We have shown that activation of D1-like DA receptors reduces non-NMDA and NMDA glutamate receptor-mediated synaptic transmission onto SNs in area X of the adult zebra finch. This modulation involves the adenylyl cyclase-PKA pathway and requires a presynaptic site of action. Combined with our previous results on excitability, these effects suggest that DA can exert complex control on the signal transformation of excitatory inputs from HVC and LMAN.

Several pieces of evidence indicate that the D1-like DA receptor-mediated reduction results from depression of presynaptic transmitter release and does not require postsynaptic modulation of receptor function: (1) both non-NMDA and NMDA receptor-mediated synaptic currents are reduced to a similar extent; (2) the reduction is associated with increased pairedpulse ratio and coefficient of variation; (3) bath-applied, but not intracellular, Rp-cAMPS blocks the reduction; and (4) the response to application of exogenous NMDA is not reduced by forskolin, even in cells in which EPSCs are significantly depressed. Thus, a presynaptic site of action is required for the depressing effects of D1-like DA agonist and forskolin. 
A priori, presynaptic depression could be achieved either by activation of D1-like DA receptors on the presynaptic terminals or through an intermediary diffusible messenger that inhibits presynaptic transmitter release. Our data showing that the adenosine A1 receptor antagonist completely abolished the forskolin-induced reduction in EPSC size (Fig. 10) strongly suggest that such presynaptic depression is mediated by adenosine as an intermediary messenger. Two pieces of evidence further constrain the mechanism for D1-like DA receptor agonist or forskolin-induced adenosine release. Because forskolin failed to reduce EPSC size in the presence of the adenosine A1 receptor antagonist, adenosine release and subsequent activation of adenosine receptors are most likely downstream from activation of PKA. Because the reduction in the EPSC was not blocked by intracellularly applied Rp-cAMPS (Fig. 8), homosynaptic adenosine release seems unlikely to be the major contributor. Taken together, these results are most consistent with the scenario shown in Figure 12. Briefly, activation of D1-like DA receptors triggers a second-messenger cascade that stimulates PKA activity, which leads to adenosine release from cellular elements other than the postsynaptic neuron being recorded; however, these could be other area $\mathrm{X}$ SNs. Adenosine then binds to adenosine A1 receptors at the presynaptic terminals, the activation of which induces inhibition of presynaptic glutamate release. A D1-like DA receptor and adenosinemediated presynaptic depression has also been reported in the ventral tegmental area of guinea pigs (Bonci and Williams, 1996).

Because adenosine is diffusible and because these effects involve adenosine release possibly from multiple sources, the specificity of the synaptic depression, i.e., which inputs are reduced, is determined primarily by diffusion range of adenosine and selective expression of the presynaptic adenosine receptors, rather than by selective expression of presynaptic DA receptors. In other words, the synaptic depression would not necessarily be specific to a given glutamatergic synapse and could affect active and passive pathways alike, thereby providing general inhibition of afferent signals from HVC and LMAN.

Interestingly, when compared with observations in the mammalian striatum, the presynaptic depression in area $\mathrm{X}$ of zebra finch is similar to the depression phenomenon reported in the nucleus accumbens. We observed a PKA-dependent and adenosinedependent presynaptic depression. In the core and shell region of nucleus accumbens, activation of D1-like DA receptors also induces presynaptic depression of glutamatergic transmission (Pennartz et al., 1992; Harvey and Lacey, 1996; Nicola et al., 1996). Harvey and Lacey (1997) further demonstrated that this depression is mediated via adenosine release. However, although the detailed mechanisms are still controversial, the current consensus suggests that the effect of D1-like DA receptor activation does not require the PKA pathway in mammalian nucleus accumbens.

It is also worth noting that we observed a forskolin-induced delayed potentiation in the NMDA receptor-mediated response in a small subset of area X spiny neurons (Fig. 11), similar to that reported in mammalian dorsal striatum (Colwell and Levine, 1995). In the dorsal striatum, the main reported effect of D1-like DA receptor agonist and forskolin is potentiation of postsynaptic glutamate receptors (Cepeda et al., 1993; Levine et al., 1996; Umemiya and Raymond, 1997; Price et al., 1999; Snyder et al., 2000), with the effect on non-NMDA EPSCs being less consistent (Cepeda et al., 1993; Levine et al., 1996). However, forskolin-induced early-onset depression has also been observed in mammalian dorsal striatum (Colwell and Levine, 1995, their Fig. 1). Thus, it is possible that there are two types of spiny neurons in area $\mathrm{X}$ and possibly the mammalian striatum, one of which responds to forskolin with enhanced postsynaptic response in addition to the nonspecific presynaptic depression. Alternatively,

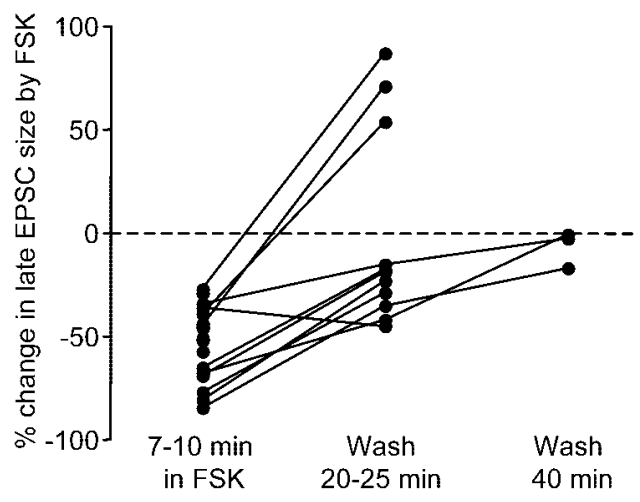

Figure 11. In a subset of neurons, forskolin induced delayed potentiation in the NMDA receptor-mediated EPSC. In 3 of 11 cells, the late EPSC size increased $\sim 20$ min after forskolin was washed out of the bath. Lines connect data points measured from the same cells.

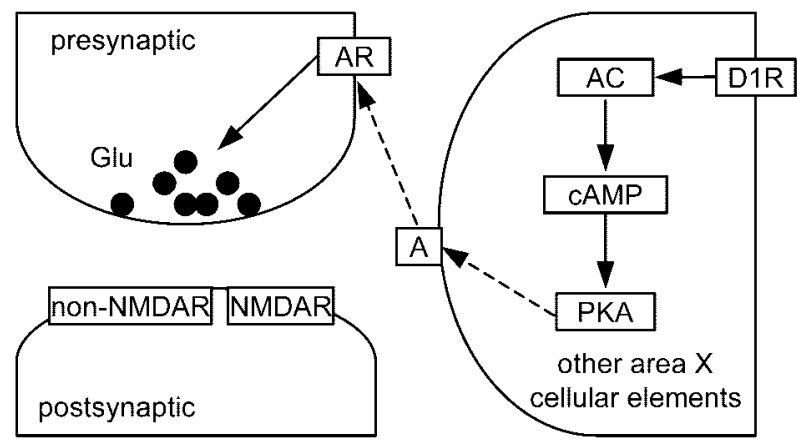

Figure 12. Hypothesized mechanism underlying the D1-like DA receptor-mediated presynaptic depression. A, Adenosine; AC, adenylyl cyclase; AR, adenosine receptor; D1R, D1-like DA receptors. Solid lines indicate activation. Dashed lines indicate release/diffusion/binding. See Discussion for more details.

the effects of PKA and D1-like DA receptor activation are region/ synapse-specific, an idea further supported by the observed facilitation of transmitter release by PKA and D1-like DA receptor activation in rat hippocampus (Trudeau et al., 1996) and substantia nigra pars reticulata (Radnikow and Misgeld, 1998), respectively, and D1like DA receptor-mediated presynaptic depression in prefrontal cortex (Gao et al., 2001). Such region/synapse specificity implies that the functional roles of DA and PKA may also differ among different brain regions.

Given that most of the glutamatergic synapses tested in area X exhibit presynaptic depression in response to D1-like DA receptors, the same direction of change as in mammalian nucleus accumbens rather than in dorsal striatum, it seems possible that area $\mathrm{X}$ processes the pallial inputs in ways specific to more cognitive/motivational signals. Area X clearly has sensorimotor functions, because it is required for vocal learning in juvenile birds (Scharff and Nottebohm, 1991), but in contrast to dramatic movement disorders often caused by malfunctioning of the basal ganglia in mammals (Denny-Brown, 1962), lesions in area X do not affect normal song production or other motor behaviors in adult zebra finches (Scharff and Nottebohm, 1991). In addition, the properties of neural activity in area $\mathrm{X}$, probed with immediate-early gene expression (Jarvis et al., 1998) or with in vivo extracellular recordings (Hessler and Doupe, 1999), vary considerably with different social contexts. These results suggest that area $\mathrm{X}$ functions are likely also cognitive and limbic, rather than strictly motor. Conceivably, both cognitive and sensorimo- 
tor information is processed in area $\mathrm{X}$, and the variation in forskolin/dopamine effects may reflect this distinction.

To explore this idea further and, more importantly, to get a better understanding of dopamine functions in the song system, it is necessary to continue teasing apart the effects of dopamine on other aspects of area X physiology, such as possible D2-like DA receptor modulation of glutamatergic synaptic transmission, dopamine modulation of inhibitory synaptic transmission and plasticity, and cellular localization of DA receptors, etc. Results obtained under carefully and systematically controlled conditions and on single aspects of area X physiology can then be integrated and serve as the foundation for elucidating the role of dopamine in the vocal behavior of songbirds and lend more general insights into dopamine function in vertebrates.

\section{References}

Blanton MG, Lo Turco JJ, Kriegstein AR (1989) Whole cell recording from neurons in slices of reptilian and mammalian cerebral cortex. J Neurosci Methods 30:203-210.

Bonci A, Williams JT (1996) A common mechanism mediates long-term changes in synaptic transmission after chronic cocaine and morphine. Neuron 16:631-639.

Bottjer SW (1993) The distribution of tyrosine hydroxylase immunoreactivity in the brains of male and female zebra finches. J Neurobiol 24:51-69.

Bottjer SW, Johnson F (1997) Circuits, hormones, and learning: vocal behavior in songbirds. J Neurobiol 33:602-618.

Bottjer SW, Miesner EA, Arnold AP (1984) Forebrain lesions disrupt development but not maintenance of song in passerine birds. Science 224:901-903.

Bottjer SW, Halsema KA, Brown SA, Miesner EA (1989) Axonal connections of a forebrain nucleus involved with vocal learning in zebra finches. J Comp Neurol 279:312-326.

Brainard MS, Doupe AJ (2000) Interruption of a basal ganglia-forebrain circuit prevents plasticity of learned vocalizations. Nature 404:762-766.

Brown LL, Schneider JS, Lidsky TI (1997) Sensory and cognitive functions of the basal ganglia. Curr Opin Neurobiol 7:157-163.

Cepeda C, Buchwald NA, Levine MS (1993) Neuromodulatory actions of dopamine in the neostriatum are dependent upon the excitatory aminoacid receptor subtypes activated. Proc Natl Acad Sci USA 90:9576-9580.

Colwell CS, Levine MS (1995) Excitatory synaptic transmission in neostriatal neurons: regulation by cyclic AMP-dependent mechanisms. J Neurosci 15:1704-1713.

del Castillo J, Katz B (1954) Quantal components of the end-plate potential. J Physiol (Lond) 124:560-573.

Denny-Brown D (1962) The basal ganglia, and their relation to disorders of movement. London: Oxford UP.

Ding L, Perkel DJ (2002) Dopamine modulates excitability of spiny neurons in the avian basal ganglia. J Neurosci 22:5210-5218.

Dolphin AC, Prestwich SA (1985) Pertussis toxin reverses adenosine inhibition of neuronal glutatmate release. Nature 316:148-150.

Dunwiddie TV, Haas HL (1985) Adenosine increases synaptic facilitation in the in vitro rat hippocampus: evidence for a presynaptic site of action. J Physiol (Lond) 369:365-377.

Dutar P, Nicoll RA (1988) A physiological role for $\mathrm{GABA}_{\mathrm{B}}$ receptors in the central nervous system. Nature 332:156-158.

Farries MA (2002) Organization and electrophysiological properties of an avian basal ganglia structure essential for song learning. $\mathrm{PhD}$ thesis, University of Pennsylvania.

Farries MA, Perkel DJ (2002) A telencephalic nucleus essential for song learning contains neurons with physiological characteristics of both striatum and globus pallidus. J Neurosci 22:3776-3787.

Gao W-J, Krimer LS, Goldman-Rakic PS (2001) Presynaptic regulation of recurrent excitation by D1 receptors in prefrontal circuits. Proc Natl Acad Sci USA 98:295-300.

Graybiel AM, Aosaki T, Flaherty AW, Kimura M (1994) The basal ganglia and adaptive motor control. Science 265:1826-1831.

Harvey J, Lacey MG (1996) Endogenous and exogenous dopamine depress EPSCs in rat nucleus accumbens in vitro via D1 receptor activation. J Physiol (Lond) 492:143-154.
Harvey J, Lacey MG (1997) A postsynaptic interaction between dopamine D1 and NMDA receptors promotes presynaptic inhibition in the rat nucleus accumbens via adenosine release. J Neurosci 17:5271-5280.

Hessler NA, Doupe AJ (1999) Social context modulates singing-related neural activity in the songbird forebrain. Nat Neurosci 2:209-211.

Jarvis ED, ScharffC, Grossman MR, Ramos JA, Nottebohm F (1998) For whom the bird sings: context-dependent gene expression. Neuron 21:775-788.

Laurenza A, Sutkowski EM, Seamon KB (1989) Forskolin: a specific stimulator of adenylyl cyclase or a diterpene with multiple sites of action. Trends Pharmacol Sci 10:442-447.

Levine MS, Li ZW, Cepeda C, Cromwell HC, Altemus KL (1996) Neuromodulatory actions of dopamine on synaptically-evoked neostriatal responses in slices. Synapse 24:65-78.

Lewis JW, Ryan SM, Arnold AP, Butcher LL (1981) Evidence for a catecholaminergic projection to area X in the zebra finch. J Comp Neurol 196:347-354.

Luo M, Ding L, Perkel DJ (2001) An avian basal ganglia pathway essential for vocal learning forms a closed topographic loop. J Neurosci 21:6836-6845.

Malinow R, Tsien RW (1990) Presynaptic enhancement shown by wholecell recordings of long-term potentiation in hippocampal slices. Nature 346:177-180.

Manabe T, Wyllie DJ, Perkel DJ, Nicoll RA (1993) Modulation of synaptic transmission and long-term potentiation: effects on paired pulse facilitation and EPSC variance in the CA1 region of the hippocampus. J Neurophysiol 70:1451-1459.

Memo M, Missale C, Carruba MO, Spano PF (1986) Pharmacology and biochemistry of dopamine receptors in the central nervous system and peripheral tissue. J Neural Transm [Suppl] 22:19-32.

Nicola SM, Kombian SB, Malenka RC (1996) Psychostimulants depress excitatory synaptic transmission in the nucleus accumbens via presynaptic D1-like dopamine receptors. J Neurosci 16:1591-1604.

Pennartz CMA, Dollemanvanderweel MJ, Kitai ST, Dasilva FHL (1992) Presynaptic dopamine D1 receptors attenuate excitatory and inhibitory limbic inputs to the shell region of the rat nucleus accumbens studied in vitro. J Neurophysiol 67:1325-1334.

Price CJ, Kim P, Raymond LA (1999) D1 dopamine receptor-induced cyclic AMP-dependent protein kinase phosphorylation and potentiation of striatal glutamate receptors. J Neurochem 73:2441-2446.

Radnikow G, Misgeld U (1998) Dopamine D1 receptors facilitate GABA synaptic currents in the rat substantia nigra pars reticulata. J Neurosci 18:2009-2016.

Reiner A, Medina L, Veenman CL (1998) Structural and functional evolution of the basal ganglia in vertebrates. Brain Res Rev 28:235-285.

Scharff C, Nottebohm F (1991) A comparative study of the behavioral deficits following lesions of various parts of the zebra finch song system: implications for vocal learning. J Neurosci 11:2896-2913.

Schultz W (1998) Predictive reward signal of dopamine neurons. J Neurophysiol 80:1-27.

Shen M, Piser TM, Seybold VS, Thayer SA (1996) Cannabinoid receptor agonists inhibit glutamatergic synaptic transmission in rat hippocampal cultures. J Neurosci 16:4322-4334.

Snyder GL, Allen PB, Fienberg AA, Valle CG, Huganir RL, Nairn AC, Greengard P (2000) Regulation of phosphorylation of the GluR1 AMPA receptor in the neostriatum by dopamine and psychostimulants in vivo. J Neurosci 20:4480-4488.

Soha JA, Shimizu T, Doupe AJ (1996) Development of the catecholaminergic innervation of the song system of the male zebra finch. J Neurobiol 29:473-489.

Sohrabji F, Nordeen EJ, Nordeen KW (1990) Selective impairment of song learning following lesions of a forebrain nucleus in the juvenile zebra finch. Behav Neural Biol 53:51-63.

Stark LL, Perkel DJ (1999) Two-stage, input-specific synaptic maturation in a nucleus essential for vocal production in the zebra finch. J Neurosci 19:9107-9116.

Trudeau L-E, Emery DG, Haydon PG (1996) Direct modulation of the secretory machinery underlies PKA-dependent synaptic facilitation in hippocampal neurons. Neuron 17:789-797.

Umemiya M, Raymond LA (1997) Dopaminergic modulation of excitatory postsynaptic currents in rat neostriatal neurons. J Neurophysiol 78:1248-1255.

Vates GE, Nottebohm F (1995) Feedback circuitry within a song-learning pathway. Proc Natl Acad Sci USA 92:5139-5143. 